\title{
ESTUDO DA OCORRÊNCIA DE ALGAROBAS (Prosopis Juliflora) POR MEIO DE DADOS DE SENSORIAMENTO REMOTO NO POLO DE JEREMOABO-BA.
}

\author{
$\underline{\text { Nerivaldo Afonso Santos }}{ }^{1}$; Elane Fiúza Borges ${ }^{2}$ \\ 1. Bolsista PIBIC/FAPESB, Graduando em Bacharelado em Geografia, Universidade Estadual de Feira de Santana, e-mail: \\ nerivaldo.geo@gmail.com \\ 2. Orientador, Departamento de Ciência Humanas e Filosofia, Universidade Estadual de Feira de Santana, e-mail: \\ elaneborges@gmail.com
}

PALAVRAS-CHAVE: Séries temporais; Indicador ambiental; Algaroba

\section{INTRODUÇÃO}

A introdução da algaroba na região semiárida do Brasil ocorreu por meio de política governamental, cuja principal ideia disseminada foi a do alto potencial forrageiro (GOMES, 1961). A origem da planta é peruana e as primeiras plantações, com apenas quatro árvores, decorreram no estado de Pernambuco, em 1942. Posteriormente houve uma disseminação das algarobas para diferentes estados, devido a adaptação da planta às condições ambientais semiáridas brasileiras e a utilidade delas na dieta animal. As primeiras translocações de espécies de uma região a outra do planeta foram intencionais e buscavam, basicamente, suprir necessidades agrícolas, florestais e outras de uso direto (LEÃO et al., 2011), assim também como ocorreu com a algaroba.

No semiárido da Bahia, averiguou-se a intensa propagação das matas de algaroba no município de Jeremoabo, nesse predomina o clima tropical semiárido, com precipitação média anual de $300 \mathrm{~mm}$ a $500 \mathrm{~mm}$. O estudo em desdobramento é realizado em área com indícios fortes de estágios avançados de degradação, o que lhe confere caráter de relevância no âmbito das discussões sobre desertificação.

Este estudo objetivou mapear as áreas de ocorrências de matas de algaroba no Pólo de Jeremoabo, através das séries temporais de imagens de satélite, bem como subsidiar os estudos sobre os impactos e a gestão ambiental.

\section{MATERIAIS E MÉTODOS}

A área de estudo abrangida pelo presente trabalho compreende o Polo Regional de Jeremoabo (Figura 1), localizado no extremo norte da Bahia, compreende 13 municípios: Antas, Novo Triunfo, Chorrochó, Rodelas, Uauá, Paulo Afonso, Glória, Pedro Alexandre, Coronel João de Sá, Macururé, Santa Brígida, Canudos e Jeremoabo, situado em uma região predominantemente escassa de precipitações, possui porção significativa de sua área caracterizada pelo clima árido e sem nenhum excedente hídrico (SEI 1998 apud VALE, 2010). 


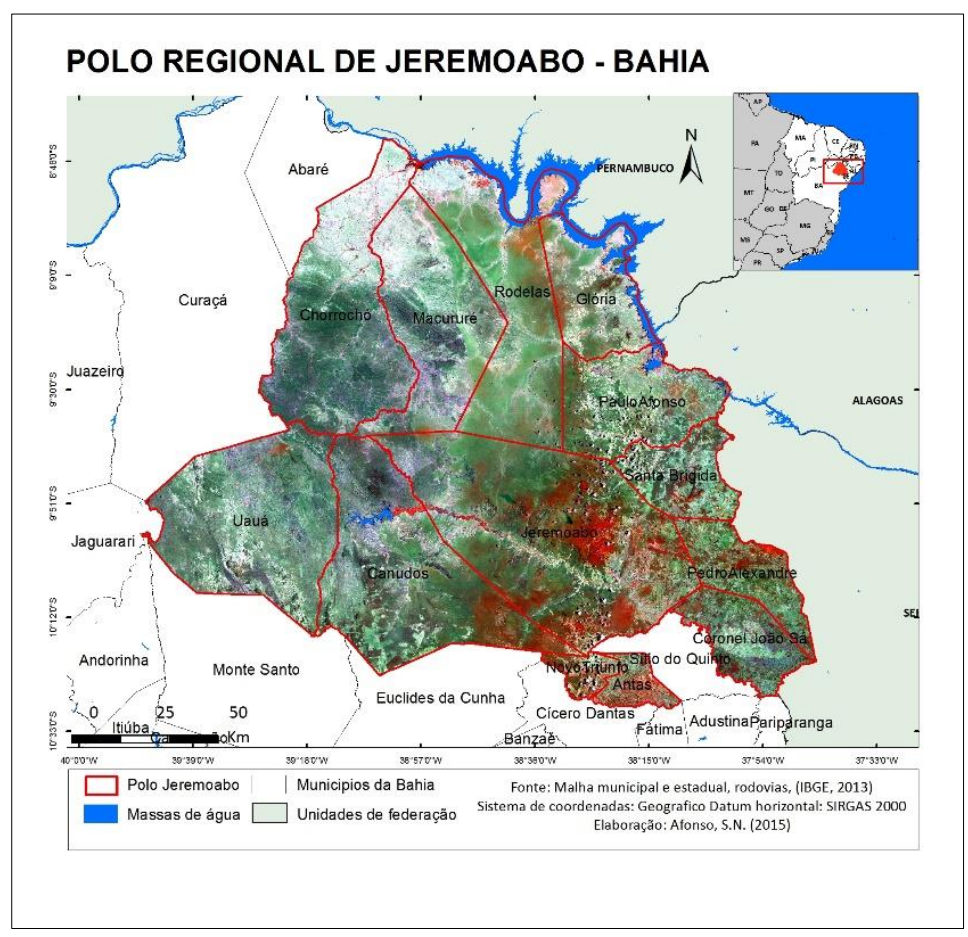

Figura 1: Mapa de localização da área de estudo

Para o desenvolvimento dessa pesquisa, inicialmente foi realizada a revisão bibliográfica a fim de se obter embasamento teórico acerca da temática abordada no plano de trabalho, bem como as principais aplicações dos dados utilizados no desenvolvimento desta pesquisa e os conceitos mais relevantes discutidos, tais como séries temporais de índice de vegetação, precipitação e sua influência na dinâmica de classes de cobertura do solo, vegetação, áreas agrícolas, bem como as influências desses fatores na degradação das terras. Para facilitar o entendimento da metodologia adotada no decorrer da pesquisa a (Figura 2) ilustra as principais etapas.

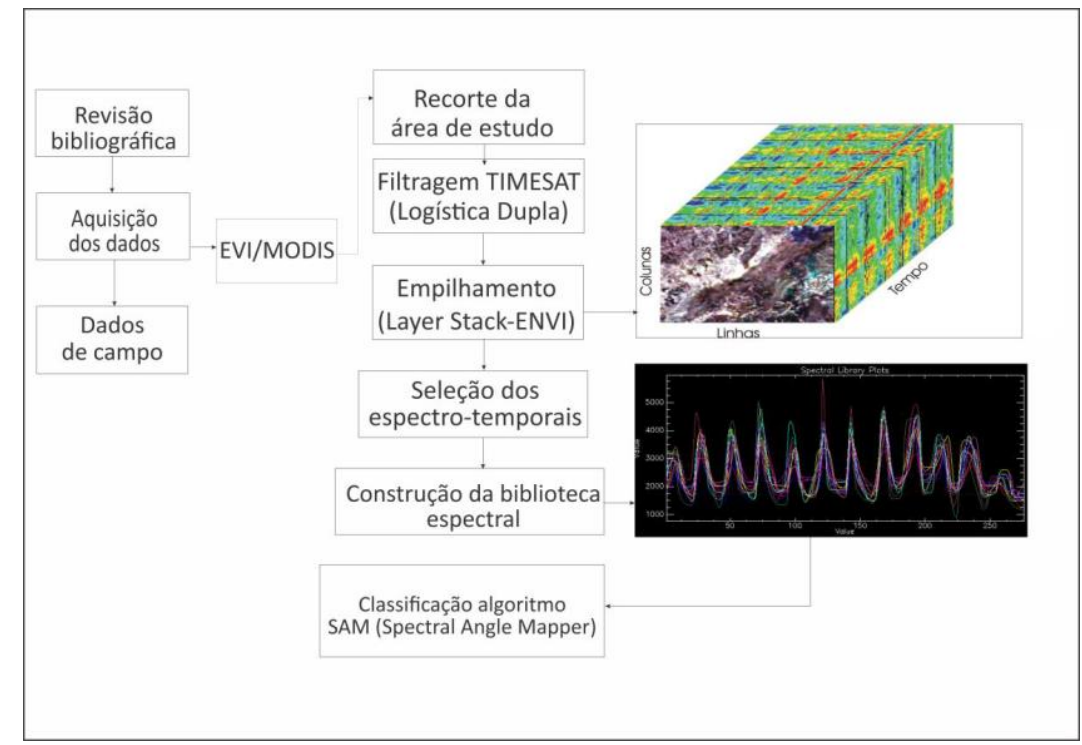

Para este estudo foi feita a aquisição de imagens MODIS/Terra, produto MOD13Q1 (Vegetation Índices 16-Day L3 Global $250 \mathrm{~m}$ ) que contém os índices de vegetação EVI, através do website (http://www.modis.cnptia.embrapa.br/geonetwork/srv/pt/main.home), este banco de dados desenvolvido pela Embrapa Informática e Agropecuária tem a proposta de facilitar ao 
usuário o acesso aos produtos MODIS, em recortes estaduais, as características dos dados são: formato GeoTIFF, Projeção: Geográfica, Datum WGS-84, resolução espacial de 250 metros, o produto MOD13Q1 possui resolução temporal de 16 dias, com cenas compostas por pixels de valor máximo neste período, foram adquiridas para este estudo um total de 276 imagens para um período compreendido entre 2001 a 2012 cerca de 23 imagens/ano. Esses dados foram recortados no software ENVI segundo os limites do Polo de Jeremoabo, organizados de maneira sequencial (cronológica) onde cada imagem foi nomeada com respectivos números que as identifiquem no tempo, compondo a série temporal.

Para se obter os espectros temporais de EVI, as imagens relativas as diferentes datas foram unidas, sintetizadas de forma que a informação multitemporal fosse contemplada em uma só imagem. Desta forma, foi possível identificar que cada "banda" da imagem se refere a um intervalo de tempo na área de estudo e não, como tradicionalmente um intervalo do espectro da radiação eletromagnética (SAMPAIO, 2007). Os espectros temporais foram organizados em sequência dos dias dos anos em ordem crescente, assim essa sequência representa a fusão do elemento tempo para a área de estudo, resultado da junção das imagens MODIS.

\section{RESULTADOS E/OU DISCUSSÃO}

A partir do mapeamento da distribuição da algaroba no Polo de Jeremoabo pode se perceber que as manchas seguem um padrão de dispersão, ocorrendo em áreas planas em geral seguindo o curso de rios e drenagens, para demonstrar essa distribuição utilizou-se o modelo digital de elevação GDEM (Global Digital Elevation Model). A imagem foi processada em ambiente SIG e as curvas de nível foram extraídas com intervalos de 30 metros para caracterização da variação de altitude na área. Posteriormente foi produzido um modelo digital de elevação TIN (Triangulated Irregular Network). A sobreposição deste produto do relevo com as áreas mapeadas com algaroba possibilitou a melhor visualização na variação de perfil do terreno em sua totalidade. Os valores de altitude variaram entre 150 a $900 \mathrm{~m}$.

De acordo com os resultados, (Figura 7) as manchas de algarobas não foram encontradas nas classes 1 (150 a $233 \mathrm{~m})$, na área que corresponde à classe 2 (234-316 m) maiores manchas foram encontradas, nas classes 3 (317-400m) e 4 (401-483 m).

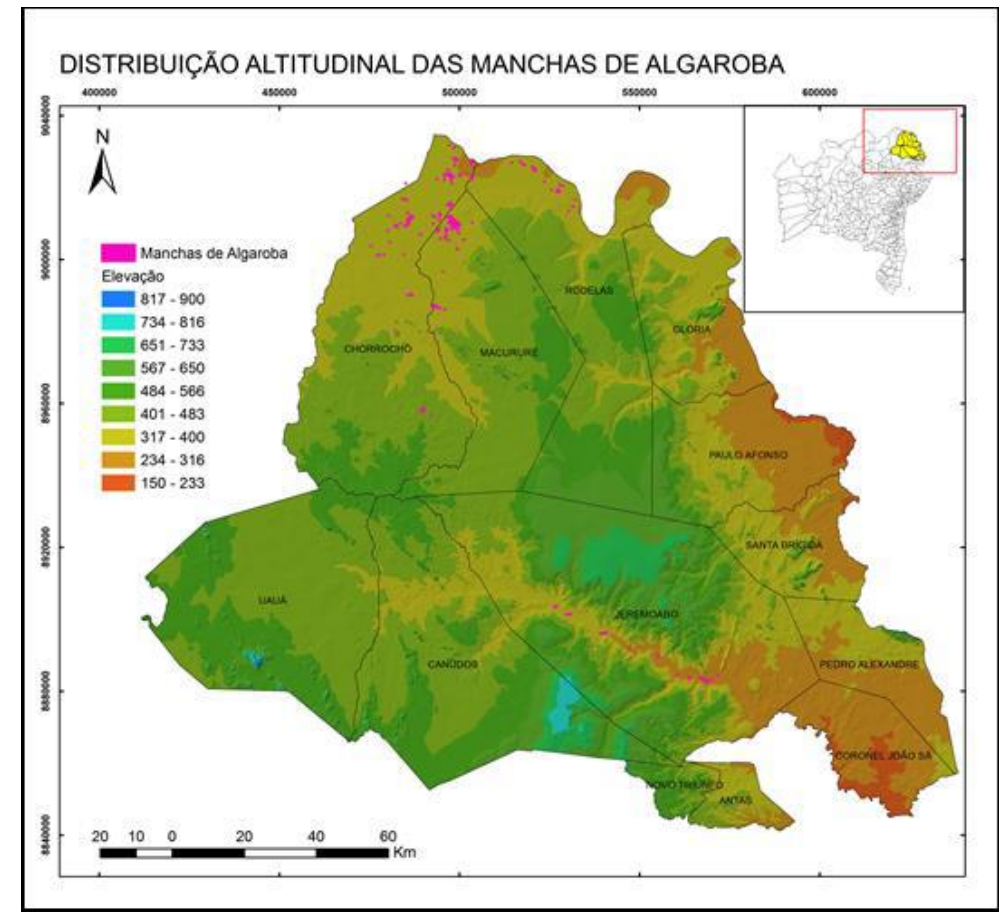


Figura 8. Localização das manchas de algaroba distribuídas nas classes de altitude.

A expansão da algaroba como espécie invasora pode estar relacionada com a produção massiva de sementes e a sua eficiente dispersão. As sementes podem ser dispersas a longas distâncias. Já em escala local, são os animais, tanto de criação quanto os selvagens, que disseminam as sementes após comerem os frutos. Outro fator que contribui para o sucesso da invasão da espécie é a capacidade da semente de permanecer dormente por até 10 anos no solo (GISP, 2005).

\section{CONSIDERAÇÕES FINAIS (ou Conclusão)}

O mapeamento das áreas de algarobas no Polo de Jeremoabo, utilizando técnicas de sensoriamento remoto e modelos de elevação digital dentro de um SIG, nos permite conhecer a distribuição espacial e altimétrica dessas matas, e consequentemente, os locais onde essas matas se desenvolvem com maior expansão e podem causar impactos à vegetação nativa. Assim, é possível desenvolver estudos futuros para entender quais impactos são causados pela proliferação desta planta e quais medidas devem ser adotadas no plano de manejo, para que essas formações não afetem a dinâmica do ecossistema local. Desta forma, esse estudo se apresenta como subsídio à futuras discussões e análise da algaroba como um indicador de degradação em áreas com características ambientais semelhantes aos municípios estudados que compõem o Pólo de Jeremoabo.

Este trabalho se insere no âmbito de vários estudos que estão sendo desenvolvidos no Grupo de Pesquisa Natureza Sociedade e Ordenamento Territorial (GEONAT) vinculado ao CNPQ que tem direcionado esforços sucessivos na construção do conhecimento de natureza socioambiental.

\section{REFERÊNCIAS}

GOMES, P. A. A algarobeira. Rio de Janeiro: Serviço de Informação Agrícola, 1961.

LEÃO, T. C. C.; ALMEIDA, W. R.; DECHOUM, M. S.; ZLLER, S. R. Espécies Exóticas Invasoras no Nordeste do Brasil: Contextualização, Manejo e Políticas Públicas. Centro de Pesquisas Ambientais do Nordeste e Instituto Hórus de Desenvolvimento e Conservação Ambiental - Recife, PE. 99 p., 2011.

PEGADO, C. M. A.; ANDRADE, L. A.; FÉLIX, L. P.; PEREIRA, I. M. Efeitos da invasão biológica de algaroba - Prosopis juliflora (Sw.) DC. Sobre a composição e a estrutura do estrato arbustivo-arbóreo da caatinga no Município de Monteiro, PB, Brasil. Acta Botânica Brasílica, v. 20, n. 4, p. 887-898, 2006.

SAMPAIO, C. S. Abordagem metodológica baseada nos dados multitemporais MODIS EVI/NDVI para classificação da cobertura vegetal na região do Parque Nacional da Chapada dos Veadeiros/GO. 73 p. Dissertação (Mestrado em Geografia) - Universidade de Brasília, Brasília. 2007.

SUPERINTENDÊNCIA DE ESTUDOS ECONÔMICOS E SOCIAIS DA BAHIA (SEI).

Balanço hídrico do estado da Bahia. Salvador: SEI, 1999

SEIA, 2014. Programa de Ação Estadual de Combate à Desertificação e Mitigação dos Efeitos da Seca (PAE-Bahia). Disponível em:< http://www.seia.ba.gov.br/planosprogramas/programa-estadual-de-combatedesertifica-o-e-mitiga-o-dos-efeitos-daseca>.Acesso: 10 junho 2016. 